Article

\title{
Green Extraction of Six Phenolic Compounds from Rattan (Calamoideae faberii) with Deep Eutectic Solvent by Homogenate-Assisted Vacuum-Cavitation Method
}

\author{
Qin Cao ${ }^{\dagger}$, Junhan $\mathrm{Li}^{\dagger}{ }^{\dagger}$, Yu Xia, Wei Li®, Sha Luo, Chunhui Ma * and Shouxin Liu*
}

Key Laboratory of Bio-Based Material Science and Technology, Ministry of Education, College of Material Science and Engineering, Northeast Forestry University, Harbin 150040, China; nefucaoqin@163.com (Q.C.); nefulijunhan@163.com (J.L.); xiayu0712@163.com (Y.X.); liwei19820927@126.com (W.L.); luo.sha.85@163.com (S.L.)

* Correspondence: mchmchmchmch@163.com (C.M.); liushouxin@126.com (S.L.); Tel.: +86-451-8219-1204 (C.M.); +86-451-8219-1502 (S.L.)

+ Authors contributed equally to this work.

Academic Editors: Elena Ibañez and Farid Chemat

Received: 28 November 2018; Accepted: 25 December 2018; Published: 29 December 2018

\begin{abstract}
A homogenate-assisted vacuum-cavitation extraction (HVE) method with a "green" solvent (a deep eutectic solvent, DES) was developed to extract phenolic compounds from rattan (Calamoideae faberii). In this study, the optimum molar ratio of choline chloride $(\mathrm{ChCl})$ and ethylene glycol (EG) was 1:3, the optimum volume ratio of $\mathrm{ChCl}-\mathrm{EG}: \mathrm{H}_{2} \mathrm{O}$ was $6: 4$, the solid-liquid ratio of $\mathrm{HVE}$ was 1:15, and the extraction time of homogenate and vacuum-cavitation were $2.0 \mathrm{~min}$ and $25 \mathrm{~min}$, respectively. Under the optimum parameters of HVE, the extraction yield of total phenolic content with ChCl-EG solution was $6.82 \mathrm{mg} / \mathrm{g}$. The higher total phenolic content was detected in fruit tissues (seeds $81.24 \pm 1.55 \mathrm{mg} / \mathrm{g}$, episperm $43.21 \pm 0.87 \mathrm{mg} / \mathrm{g}$, and arillus $38.47 \pm 0.74 \mathrm{mg} / \mathrm{g}$ ), followed by in leaves (sheath $19.5 \pm 0.38 \mathrm{mg} / \mathrm{g}$ and blade $17.81 \pm 0.33 \mathrm{mg} / \mathrm{g}$ ). In addition, the content of specific phenolic compounds in aqueous and DES extracts was determined. Chlorogenic acid was the most abundant phenol in most organs of the rattan plant. Gallic acid was mainly distributed in the arillus; protocatechuic acid was mainly distributed in the arillus, sheath, and blade; protocatechuic aldehyde was mainly distributed in the blade, seed, and sheath; (+)-catechins were mainly distributed in the episperm, seed, and sheath; and epigallocatechin gallate was mainly distributed in the blade. The recovery rates of gallic acid, protocatechuic acid, protocatechuic aldehyde, (+)-catechins, chlorogenic acid, and epigallocatechin gallate were $93.77 \%, 94.09 \%, 97.32 \%$, $97.83 \%, 94.41 \%$, and $92.47 \%$, respectively, by AB-8 resin.
\end{abstract}

Keywords: Rattan (Palmae); phenolic compounds; deep eutectic solvent (DES); homogenate-assisted vacuum-cavitation extraction (HVE); RP-HPLC

\section{Introduction}

As a class of natural "green" solvents, deep eutectic solvents (DESs) have attracted increased research attention during recent years because of their excellent characteristics, and represent a cheap alternative to ionic liquids (ILs) [1-3]. DESs can be used in a wide range of applications such as organic synthesis, catalysis, electrochemistry, and nanotechnology [4-6]. Moreover, DESs are suitable for extraction processes because of their negligible volatility at room temperature, nontoxicity, non-reactivity with water, biodegradability, and low environmental and economic impact [7-9]. Meanwhile, the rate of articles being published on natural-products separation is increasing. In the 
past five years, a few dozen interesting papers focusing on cleaner production procedures based on both solid-liquid extraction using DESs and homogenate-assisted vacuum-cavitation extraction have appeared.

In recent years, homogenate technology has been used to extract active compounds from various materials [10]. In the homogenization process, plant materials are pulverized using strong mechanical force, and the liquid shear force in the material-solvent mixture allows the solvent to penetrate into the material easily, thereby facilitating the fast dissolution of target compounds. In a homogenate treatment, material pulverization and solvent extraction are completed in one step. Therefore, this method has many advantages in a cleaner production process, including short operation time, no powder dust pollution, low extraction temperature, and high efficiency.

Recently, researchers in the fields of analytical chemistry and sample preparation have focused their attention on the cavitation effect, which can be classed into acoustic cavitation [11] or hydrodynamic cavitation [12] according to the mode of cavity formation [13].

The benefits of ultrasonic cavitation in extraction are the intensification of mass transfer and cell disruption, improved penetration, and capillary effects [14,15]. However, the use of high-frequency ultrasonic waves for cavitation leads to an increase in the solvent temperature. This increases energy consumption and limits the scale of industrial production. Recently, therefore, negative-pressure cavitation extraction and hydrodynamic cavitation, which require less energy and have lower energy dissipation, have been used in sequence to extract natural products from plants in a closed cleaner production process. The vacuum-cavitation extraction method has been used to extract polysaccharides [16], alkaloids [17], isoflavones [18], stilbenes [19], and seed oil [20] from plant materials.

Rattan is a barbed climbing monocotyledonous plant in the family Palmae (Angiospermae, Monocotyledoneae, Principes) [21]. It is one of the most important representatives of this branch in the tropics, and is popularly known as "green gold". Wild rattan is distributed in Indonesia, the Philippines, Malaysia, and Thailand, and is widely cultivated in the tropical Americas, tropical Asia, and in the Pacific Islands [22]. The plant taxonomist Dransfield separated the Palmae into 13 genera, with about 610 species and subspecies known around the world [22]. Previous studies have mainly focused on the commercial aspects of rattan cane as a raw material for furniture and handicraft industries [23], rather than its chemical composition or biological activities. In general, only the cane part of rattan is used, and the other parts are waste materials. The aim of this study, therefore, was to extract phenolic compounds from rattan waste parts (blade, sheath, episperm, arillus, seed, and stem). There are two benefits of this approach: it uses rattan waste resources, and provides phenolic compounds for use as active ingredients.

Phenolic compounds can be divided into several classes, including phenolic acids and their derivatives, dehydrodiferulates and dehydrotriferulates, flavan-3-ol monomers, and others [24]. At present, the main research reports of phenolic compounds are gallic acid, protocatechuic acid, protocatechuic aldehyde, catechin, chlorogenic acid and epigallocatechin gallate. Their antioxidant [25-27] and free-radical scavenging activities [28-30] re excellent for a wide range of industrial applications, such as food additives and colorants, which can be attributed to the phenolic hydroxyl groups they possess.

In this study, a DES extraction method combining homogenate technology with vacuum-cavitation digestion was used to accelerate the extraction of phenolic compounds from rattan waste materials (Palmae, Calamoideae, Trachycarpus). The extraction mechanism of homogenate-assisted vacuum-cavitation with deep eutectic solvent was studied in detail, and the innovation lies in the formation of hydrogen bonds in DES that decrease the barrier of plant cell walls recalcitrance. And this effect was worked synergistically with homogenization extraction and negative-pressure cavitation extraction. In addition, a reversed-phase high-performance liquid chromatography (RP-HPLC) method was used to quantify six phenolic compounds simultaneously. Finally, the content distribution of the six different phenolic compounds in different parts of the rattan plant was investigated. 


\section{Results and Discussion}

\subsection{Chemical Analysis of Rattan Materials}

The chemical composition of rattan $(100.0 \mathrm{~g})$ was as follows: cellulose $(9.56 \% \pm 0.26 \%)$, hemicellulose $(50.97 \% \pm 0.65 \%)$, lignin $(6.57 \% \pm 0.07 \%)$, aqueous extracts (which was extracted with pure water) $(3.5 \% \pm 0.08 \%)$, and ethanolic extracts $(9.85 \% \pm 0.2 \%)$. The content of phenolic compounds in the aqueous extract (extracted by heating and stirring with water for $6 \mathrm{~h}$ ) was $0.74 \% \pm 0.01 \%$. The content of phenolic compounds in the ethanolic extracts (extracted by Soxhlet extraction for $6 \mathrm{~h}$ with $80 \%$ ethanol solution) was $2.29 \% \pm 0.01 \%$.

\subsection{RP-HPLC Analysis of Phenolic Compounds}

For the HPLC-UV analysis, methanol-water-phosphoric acid $(10: 88: 2, v / v / v)$ was used as the mobile phase at a flow rate of $1.0 \mathrm{~mL} / \mathrm{min}$. The injection volume was $10 \mu \mathrm{L}$ and the column temperature was $25^{\circ} \mathrm{C}$. Precision the standard $10.0 \mathrm{mg}$, and then set capacity to $10 \mathrm{~mL}$, obtained the single standard reserve solution. And then mixed the single standard reserve solution, obtained the mixing standards reserve solution $(0.167 \mathrm{mg} / \mathrm{mL}$ for each phenolic standard). Finally, diluted the mixing standards by 2 times in turn, and were detected by measuring absorbance at $274 \mathrm{~nm}$ during a run time of $60 \mathrm{~min}$ (Figure 1). Table 1 shows the retention time, the corresponding calibration curves, the limit of quantity (LOQ) and the limit of detection (LOD) for gallic acid, protocatechuic acid, protocatechuic aldehyde, (+)-catechins, chlorogenic acid, and EGCG.

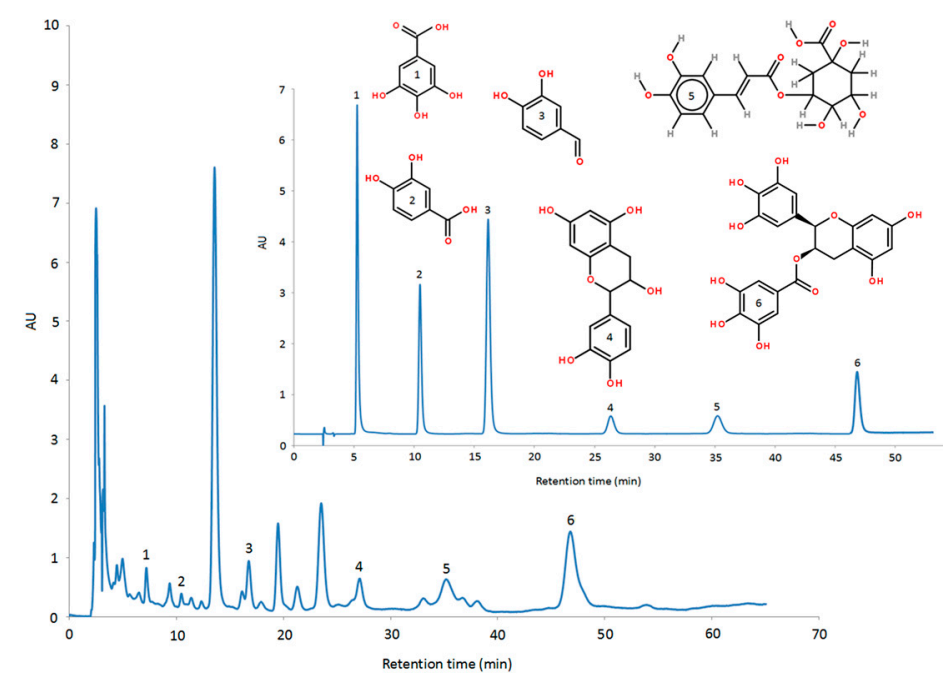

Figure 1. High-performance liquid chromatography (HPLC) of phenolic compounds standards (inner) and Rattan sample (outer).

Table 1. Calibration curves and limits of detection for six phenolic compounds.

\begin{tabular}{|c|c|c|c|c|c|c|}
\hline No. & $\begin{array}{l}\text { Phenolic } \\
\text { Compounds }\end{array}$ & $\begin{array}{l}\text { Retention } \\
\text { Time (min) }\end{array}$ & $\begin{array}{c}\text { Corresponding Calibration } \\
\text { Curves }\end{array}$ & $R^{2}$ & $\begin{array}{c}\text { LOQ } \\
(\mathrm{mg} / \mathrm{mL})\end{array}$ & $\begin{array}{l}\text { LOD } \\
(\mu \mathrm{g} / \mathrm{mL})\end{array}$ \\
\hline 1 & Gallic acid & 5.2 & $Y=3.07 \times 10^{7} X+4.01 \times 10^{4}$ & 0.9999 & $0.0157-0.1672$ & 4.33 \\
\hline 2 & $\begin{array}{l}\text { Protocatechuic } \\
\text { acid }\end{array}$ & 10.4 & $Y=5.35 \times 10^{7} X+4.96 \times 10^{4}$ & 0.9999 & $0.0157-0.1676$ & 4.75 \\
\hline 3 & $\begin{array}{l}\text { Protocatechuic } \\
\text { aldehyde }\end{array}$ & 16.3 & $Y=3.10 \times 10^{7} X+2.34 \times 10^{4}$ & 0.9999 & $0.0157-0.1671$ & 4.71 \\
\hline 4 & $(+)$ catechins & 26.7 & $Y=1.50 \times 10^{7} X+2.91 \times 10^{4}$ & 0.9992 & $0.0156-0.1669$ & 4.65 \\
\hline 5 & $\begin{array}{l}\text { Chlorogenic } \\
\text { acid }\end{array}$ & 35.1 & $Y=2.36 \times 10^{7} X+9.57 \times 10^{4}$ & 0.9999 & $0.0157-0.1676$ & 4.48 \\
\hline 6 & EGCG & 46.8 & $Y=3.13 \times 10^{7} X+2.32 \times 10^{5}$ & 0.9996 & $0.0157-0.1670$ & 4.92 \\
\hline
\end{tabular}




\subsection{Screening of DES Solution}

\subsubsection{Effect of DES Composition on Extraction Efficiency of Phenolic Compounds}

DESs are composed of a hydrogen bond acceptor (HBA) and a hydrogen bond donor (HBD), in contrast to ILs, which consist of anions and cations. The interactions between HBA and HBD involve mostly hydrogen bonding, occasional electrostatic forces, and van der Waals interactions. The most important intramolecular bonds in DESs are the hydrogen bonds between the HBD and halide anions [3]. Through the preliminary experiments, Choline chloride $(\mathrm{ChCl})$ as a kind of hydrogen bond acceptor, polyol as hydrogen bond donor showed a better extraction efficiency of phenolic acid compounds. Thus, in this study, the polyol (ethylene glycol (EG), glycerol (GI) and 1,4-butanediol (BDO)) as hydrogen bond donor was screened. And the extraction yield of the total phenol content as the response value, the different DESs (ChCl-EG, ChCl-GI, ChCl-BDO) with the same volume ratio of DES: $\mathrm{H}_{2} \mathrm{O}$ (6:4) was investigated. The results were shown in Figure 2. In Figure 2a, the extraction yields when using ChCl-EG, ChCl-Gl, and ChCl-BDO with different molar ratios (1:1, 1:2, 1:3, 1:4, 1:5) are displayed. In all three DESs, hydrogen bonds are shared between the HBD (polyol) and chloride ions from $\mathrm{ChCl}(\mathrm{HBA})$, as showed in Figure S1, for polyols, there are more than two hydroxyl groups in the molecule that can form large molecules by forming intramolecular hydrogen bonds, and can also form intermolecular hydrogen bonds with $\mathrm{ChCl}$. The greater number of $\mathrm{OH}$ was provided by GI, when the same molar ratios of polyol, but the better water absorbent performance of GI may form the intermolecular hydrogen bonds, resulting in a decrease in the number of hydrogen bonds with $\mathrm{ChCl}$. Compared with $\mathrm{BDO}$, the steric effects to the formation of intermolecular hydrogen bonds with is $\mathrm{ChCl}$ smaller. Therefore, the extraction yield of total phenolic compounds with ChCl-EG $(6.97 \pm 0.11 \mathrm{mg} / \mathrm{g})$ was higher than that with ChCl-Gl $(4.79 \pm 0.13 \mathrm{mg} / \mathrm{g})$ and $\mathrm{ChCl}-\mathrm{BDO}(4.77 \pm 0.14 \mathrm{mg} / \mathrm{g})$, and 1:3 was the optimum molar ratio of $\mathrm{ChCl}$ and polyol.

\subsubsection{Effect of Water Content in DES on Extraction Efficiency of Phenolic Compounds}

The main disadvantage of DESs is their high viscosity, which not only hinders the mass transport from plant matrices to solution but also leads to handling difficulties (e.g., in filtration, decantation, and dissolution). Thus, the addition of water to DES was a vital factor affecting the extraction capacity of the target compounds. From Figure 2b, with the volume ratio of ChCl-EG: $\mathrm{H}_{2} \mathrm{O}$ decreasing, the extraction efficiency of total phenolic compounds firstly increased, and declined gradually thereafter (Figure S2). The highest extraction yield $(6.97 \pm 0.11 \mathrm{mg} / \mathrm{g})$ was achieved with $40 \%$ water (volume percentage) in ChCl-EG solution. The addition of water decreases the viscosity, which increases the osmotic effect of DES solution, enhancing the mass transfer from plant matrices to solution, and thus resulting in boosted extraction efficiency. However, excessive water addition can increase the chemical polarity of DES solution, and the dissolve of phenolic compounds increased according to the "similar solubility principle". Therefore, the volume ratio of ChCl-EG: $\mathrm{H}_{2} \mathrm{O}=6: 4$ was used for further extraction processes. 

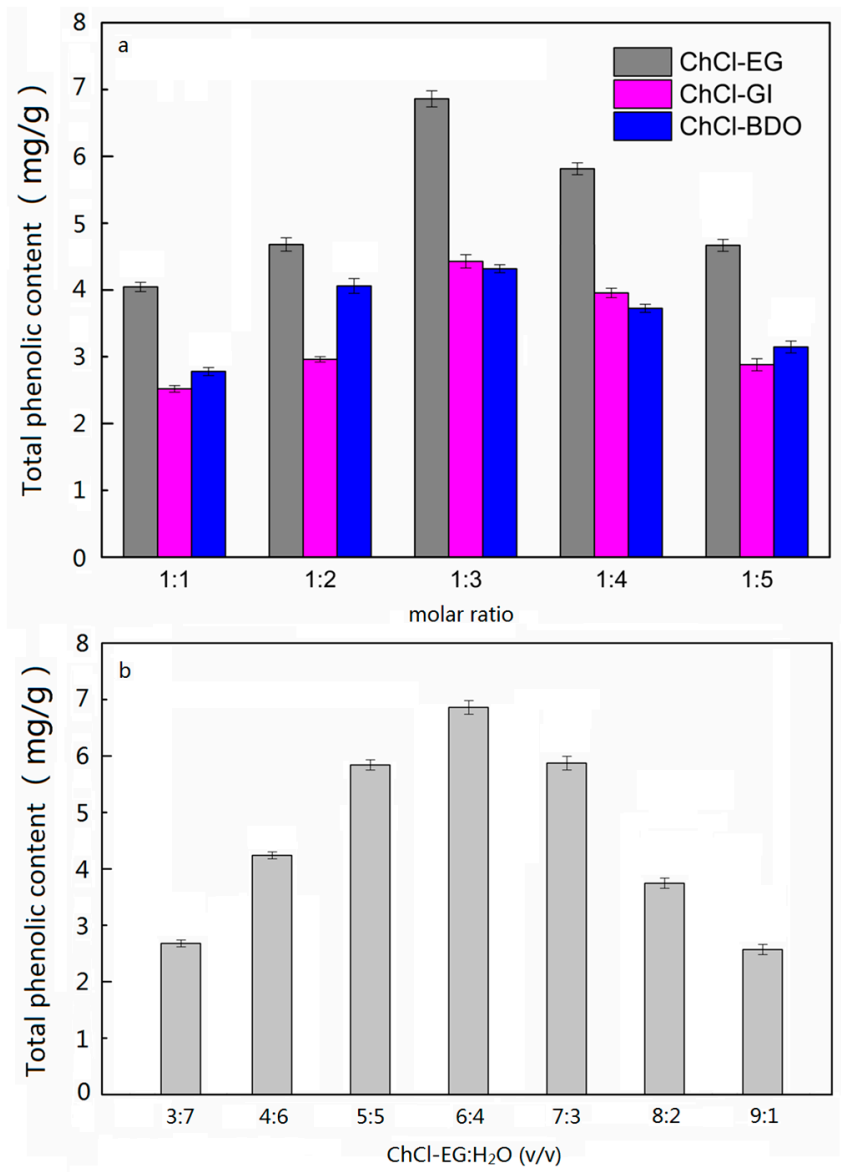

Figure 2. Screening of deep eutectic solvent (DES), including composition of DES (a) and amount of water added to DES (b).

\subsection{Factors Affecting Total Phenolic Content after Homogenate-Assisted Extraction}

\subsubsection{Solid-Liquid Ratio}

During the extraction step, an excessively high solvent content may complicate the extraction process, create unnecessary wastage, and increase energy consumption during recycling, while an excessively low solvent content may lead to incomplete extraction. To evaluate the effect of the solid-liquid ratio during extraction, $20.0 \mathrm{~g}$ dried rattan material was mixed with DES and aqueous solution at a range of different solid-liquid ratios $(1: 5,1: 8,1: 10,1: 12,1: 15$, and 1:20 $\mathrm{g} / \mathrm{mL})$, and then the samples were homogenized for $2.0 \mathrm{~min}$. As shown in Figure 3, the total phenolic content increased with increasing solvent volume up to a solid-liquid ratio of $1: 15$ (total phenolic content, $8.41 \pm 0.14 \mathrm{mg} / \mathrm{g}$ with aqueous solution; $8.87 \pm 0.16 \mathrm{mg} / \mathrm{g}$ with DES), but did not increase significantly as the solid-liquid ratio increased further. Therefore, considering the need to extract the total phenolic content while minimizing the energy consumption of solvent recovery, the 1:15 solid-liquid ratio was used for further HAE experiments. 


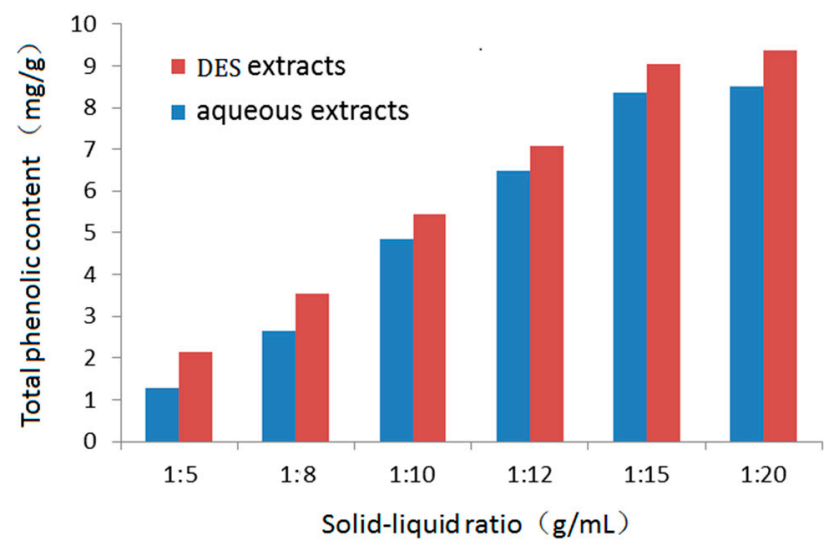

Figure 3. Effect of solid-liquid ratio during homogenate-assisted extraction on total phenolic content.

\subsubsection{Duration of Homogenate-Assisted Extraction}

To investigate the effect of extraction time on the total phenolic content after homogenate extraction, $20.0 \mathrm{~g}$ dried sample was mixed with DES solution or pure water (ratio, 1:15), and then the homogenate was extracted for $0.5,1.0,1.5,2.0,2.5$, or $3.0 \mathrm{~min}$. As shown in Figure 4, as the extraction time increased, the total phenolic content initially increased. After homogenate extraction for $2.0 \mathrm{~min}$ (total phenolic content, $1.97 \pm 0.04 \mathrm{mg} / \mathrm{g}$ with pure water; $8.75 \pm 0.16 \mathrm{mg} / \mathrm{g}$ with DES), there were no further increases in the total phenolic content. Therefore, 2.0 min was selected as the optimal duration time for homogenate extraction of phenolic compounds.

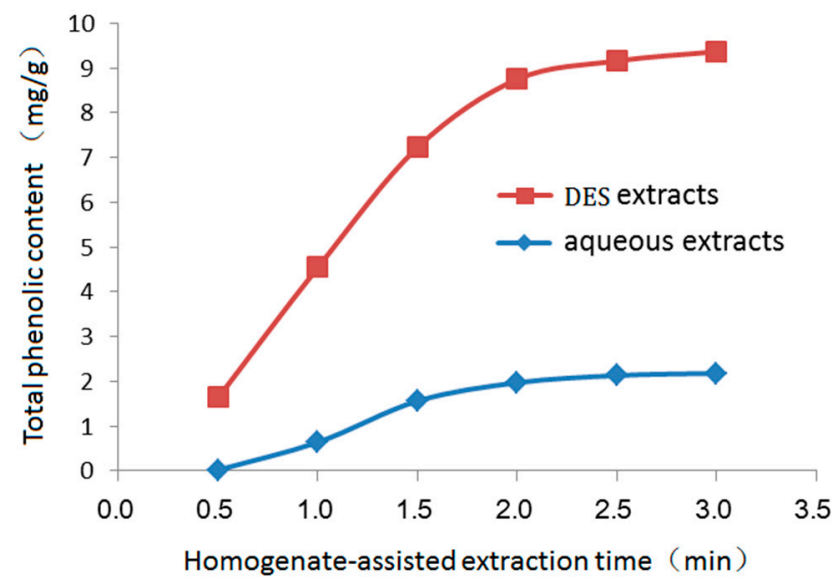

Figure 4. Effect of duration of homogenate-assisted extraction on total phenolic content.

\subsubsection{Homogenate-Assisted Extraction Mechanism}

The homogenate-assisted extraction process includes the pulverization of raw material, and the mixing of the solid (plant material) and the liquid (extraction solvent) phases. In essence, it is a solid-liquid mass transfer process enhanced using an external force [10]. In Figure 5, the formation of DES liquid film on the plant cell surface was analyzed, from a microscopic point of view. Three effects are involved in homogenate-assisted extraction process: (1) The shearing action reduces the size of the large solid particles and destroys most of the plant cell walls. At the same time, a liquid membrane layer which contained more hydrogen bonds forms at the cell surface, the permeability of cell was increased and the phenolic acids are released into the solvent; (2) Shearing of solid particles into smaller pieces, leading to an increase in the specific surface area of the solid-liquid phase interface, and an increase in the area of the liquid membrane attached to the solid surface. This increases the mass transfer rate from solid to liquid, and shortens the extraction time; and (3) Partial disappearance of the liquid membrane. During the homogenization process, the thickness of the liquid membrane 
(also known as the dynamic membrane) changes as the stirring speed changes, becoming thinner at higher stirring speeds. In addition, the dissolution rate of target components in plant cells increases with stronger turbulence in the mixture. Therefore, the homogenate extraction process is actually an unstable and non-equilibrium process by which active components are released from plant cells and dissolved into the solvent [31,32]. In short, as the homogenate-assisted extraction is prolonged, the plant particle size becomes smaller, and the smaller particle size can provide a higher specific surface area, thereby shortening the mass transfer path and improving mass transfer efficiency.

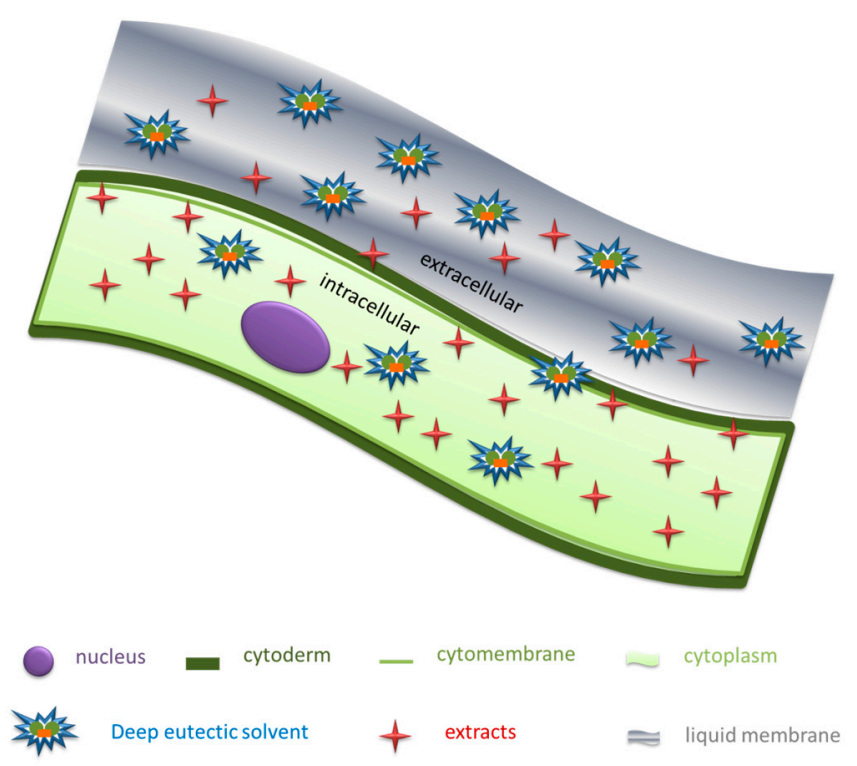

Figure 5. Unstable and non-equilibrium diffusion model of release of target components from plant cells.

\subsection{Factors Affecting Cavitation Extraction}

\subsubsection{Vacuum-Cavitation Time}

The generation of vacuum-cavitation by negative pressure is a cheap and energy-efficient method. As shown in Figure 6, extractions were carried out at negative pressure with a $180 \mathrm{~W}$ vacuum pump for 5, 10, 15, 20, 25, 30, 35, 40, and $45 \mathrm{~min}$. The total phenolic content increased significantly as the treatment time increased from 0 to $25 \mathrm{~min}$ (total phenolic content after $25 \mathrm{~min}$ vacuum-cavitation, $21.44 \pm 0.44 \mathrm{mg} / \mathrm{g}$ with pure water; $90.33 \pm 1.89 \mathrm{mg} / \mathrm{g}$ with DES). However, the content increased only slightly as the vacuum-cavitation treatment time was further increased from $25 \mathrm{~min}$ to $45 \mathrm{~min}$ (total phenolic content after $45 \mathrm{~min}$ vacuum-cavitation, $23.65 \pm 0.38 \mathrm{mg} / \mathrm{g}$ with pure water; $96.47 \pm 2.02 \mathrm{mg} / \mathrm{g}$ with DES). Therefore, $25 \mathrm{~min}$ was used as the vacuum-cavitation time in further extraction experiments. 


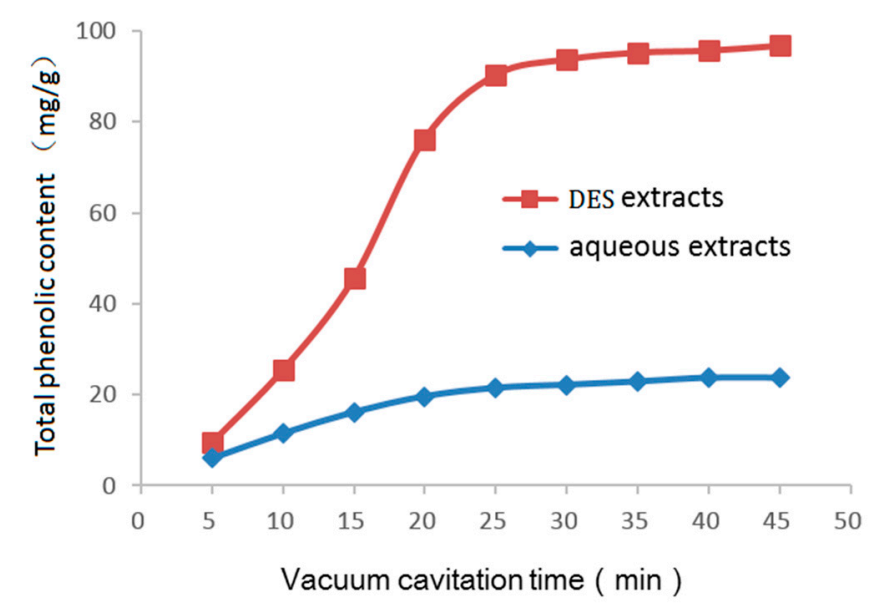

Figure 6. Effect of vacuum-cavitation time on the total phenolic content.

\subsubsection{Negative-Pressure Cavitation Effect}

Next, after optimizing the extraction times and volumes as described above, a comparative study was conducted to compare the vacuum-cavitation effect with the well-known ultrasonic cavitation effect. Cavitation is a fluid mechanics phenomenon in which millions of tiny vapor bubbles sequentially form, grow, and collapse in the liquid phase or at the liquid-solid interface. As shown in Figure 7, with negative pressure, the formation and expansion of bubbles in the turbulent liquid, and the turbulence generated in the liquid-solid mixture, accelerated the collapse of bubbles, which was controlled by the vacuum power. The bubbles produced during ultrasonic extraction formed on the solid surface, while those produced under negative pressure grew faster and had a shorter collapse cycle. Moreover, there was a vigorous stirring effect of solvent which contained more hydrogen bonds under negative pressure, so that the surface of the cell walls broke down and the solvent readily diffused into the material, and hydrogen bonds that decrease the barrier of plant cell walls recalcitrance. In this system, rapid mass transfer was accomplished [33], and consequently, the target compounds were transferred from the matrix into the solvent [34]. As the treatment time increased from 0 to $20 \mathrm{~min}$, the total phenolic content increased significantly. The cavitation extraction with negative pressure at room temperature can avoid being heated resulting in isomerization. After treatment $25 \mathrm{~min}$, the total phenolic yield increased minimally. 


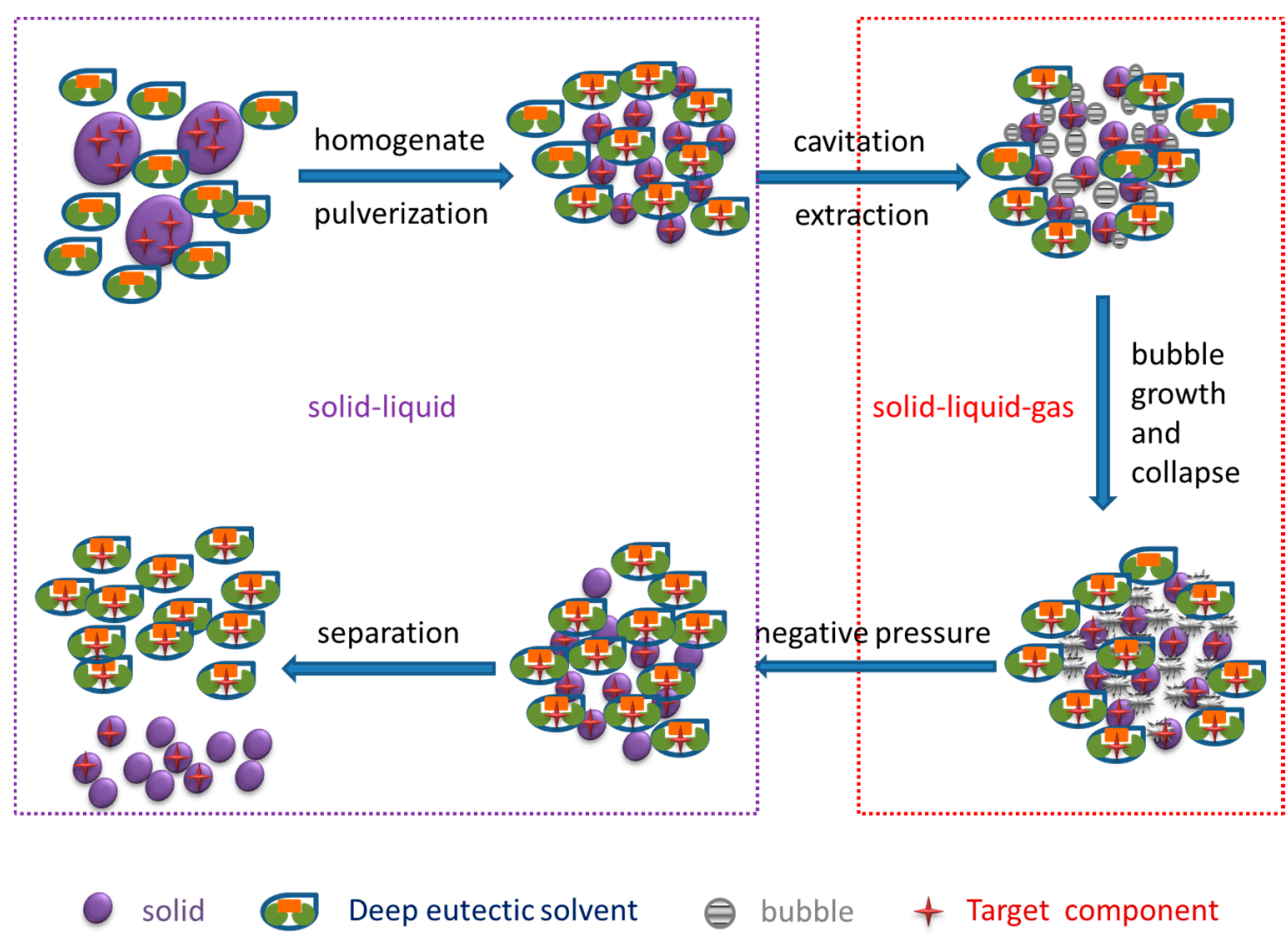

Figure 7. Schematic diagram of homogenate-assisted vacuum-cavitation effect.

\subsection{Content Distribution of Total Phenolic in the Rattan Plant}

The total phenolic contents in different parts of the rattan plant were determined using the Folin-Ciocalteu method. With DES and pure water as the extraction solvents, the optimized HVE method was used to extract phenolic compounds from rattan. The total phenolic contents in DES and aqueous extracts from various organs are shown in Figure 8. The highest total phenolic content was in fruit tissues, including the seeds $(81.24 \pm 1.55 \mathrm{mg} / \mathrm{g}$ in DES extracts; $8.75 \pm 0.17 \mathrm{mg} / \mathrm{g}$ in aqueous extracts), episperm ( $43.21 \pm 0.87 \mathrm{mg} / \mathrm{g}$ in DES extracts; $4.30 \pm 0.08 \mathrm{mg} / \mathrm{g}$ in aqueous extracts), and arillus (38.47 $\pm 0.74 \mathrm{mg} / \mathrm{g}$ in DES extracts; $3.81 \pm 0.07 \mathrm{mg} / \mathrm{g}$ in aqueous extracts); followed by the leaf tissues, including the sheath $(19.5 \pm 0.38 \mathrm{mg} / \mathrm{g}$ in DES extracts; $1.94 \pm 0.04 \mathrm{mg} / \mathrm{g}$ in aqueous extracts) and blade (17.81 $\pm 0.33 \mathrm{mg} / \mathrm{g}$ in DES extracts; $1.79 \pm 0.03 \mathrm{mg} / \mathrm{g}$ in aqueous extracts). The lowest total phenolic content was in the stem $(5.11 \pm 0.10 \mathrm{mg} / \mathrm{g}$ in DES extracts; $0.52 \pm 0.01 \mathrm{mg} / \mathrm{g}$ in aqueous extracts).

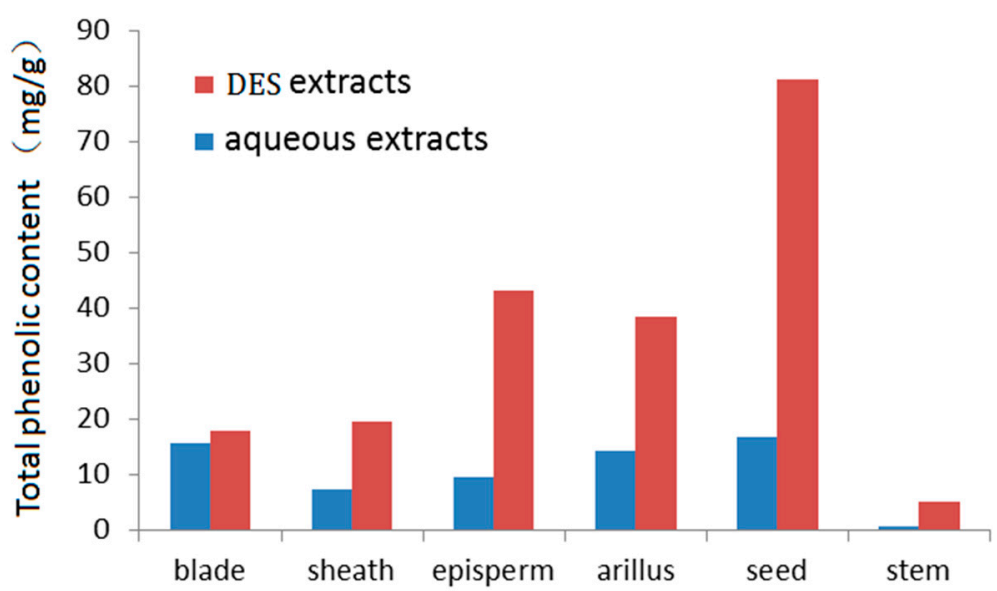

Figure 8. Contents of total phenolic in rattan plant. 


\subsection{Differences in Specific Phenolic Compound among Different Parts of Rattan}

Six different phenolic compounds were simultaneously quantified in different parts of rattan using the RP-HPLC method, namely gallic acid, protocatechuic acid, protocatechuic aldehyde, (+)-catechins, chlorogenic acid, and EGCG. Chlorogenic acid was the most abundant phenolic compound in all organs except for the arillus (Figure 9). In the aqueous extract from the rattan blade, the concentrations of gallic acid, protocatechuic acid, protocatechuic aldehyde, (+)-catechins, chlorogenic acid, and EGCG were $1.356 \pm 0.024 \mathrm{mg} / \mathrm{g}, 0.032 \pm 0.001 \mathrm{mg} / \mathrm{g}, 0.055 \pm 0.001 \mathrm{mg} / \mathrm{g}, 0.225 \pm 0.004 \mathrm{mg} / \mathrm{g}$, $18.919 \pm 0.378 \mathrm{mg} / \mathrm{g}$, and $1.768 \pm 0.034 \mathrm{mg} / \mathrm{g}$, respectively (Figure $9 \mathrm{a}$ ). The highest EGCG content was in the blade $(1.768 \pm 0.034 \mathrm{mg} / \mathrm{g}$ in DES extracts; $1.440 \pm 0.028 \mathrm{mg} / \mathrm{g}$ in aqueous extracts), while EGCG was present at only trace amounts in other organs (undetectable by HPLC). In the aqueous extracts from the rattan sheath, the concentrations of gallic acid, protocatechuic acid, protocatechuic aldehyde, (+)-catechins, and chlorogenic acid were $1.689 \pm 0.031 \mathrm{mg} / \mathrm{g}, 0.097 \pm 0.002 \mathrm{mg} / \mathrm{g}, 0.018 \pm 0.001 \mathrm{mg} / \mathrm{g}$, $1.132 \pm 0.028 \mathrm{mg} / \mathrm{g}$, and $5.785 \pm 0.116 \mathrm{mg} / \mathrm{g}$, respectively (Figure $9 \mathrm{a}$ ). In the aqueous extracts of rattan episperm, only (+)-catechins and chlorogenic acid were detected, at concentrations of $8.52 \pm 0.155 \mathrm{mg} / \mathrm{g}$ and $9.291 \pm 0.172 \mathrm{mg} / \mathrm{g}$, respectively. In the aqueous extract from the arillus, only gallic acid, protocatechuic acid, and chlorogenic acid were detected, at concentrations of $2.039 \pm 0.040 \mathrm{mg} / \mathrm{g}, 0.071 \pm 0.003 \mathrm{mg} / \mathrm{g}$, and $0.320 \pm 0.006 \mathrm{mg} / \mathrm{g}$, respectively. In the aqueous extract from rattan seeds, the concentrations of gallic acid, protocatechuic aldehyde, $(+)$-catechins, and chlorogenic acid were $0.038 \pm 0.003 \mathrm{mg} / \mathrm{g}, 0.046 \pm 0.003 \mathrm{mg} / \mathrm{g}, 3.177 \pm 0.061 \mathrm{mg} / \mathrm{g}$, and $14.399 \pm 0.288 \mathrm{mg} / \mathrm{g}$, respectively. In the aqueous extracts from rattan stems, only gallic acid and chlorogenic acid were detected, at concentrations of $0.674 \pm 0.018 \mathrm{mg} / \mathrm{g}$ and $5.209 \pm 0.115 \mathrm{mg} / \mathrm{g}$, respectively.

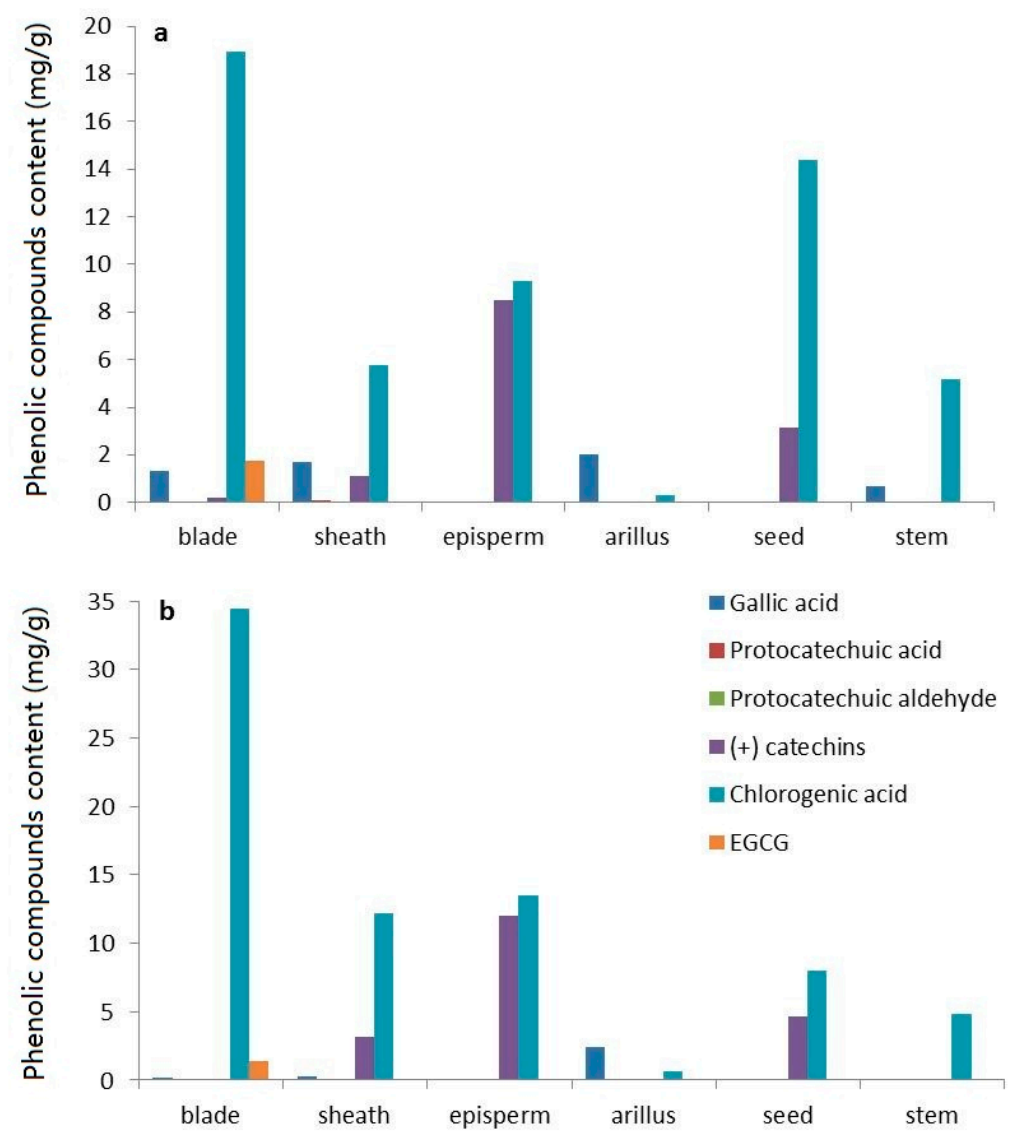

Figure 9. Contents of six phenolic compounds in aqueous extracts (a) and DES extracts (b) from different parts of rattan plant. 
As shown in Figure 9b, in DES extracts from rattan blades, the concentrations of gallic acid, protocatechuic acid, protocatechuic aldehyde, $(+)$-catechins, chlorogenic acid, and EGCG were $0.163 \pm 0.005 \mathrm{mg} / \mathrm{g}, \quad 0.014 \pm 0.001 \mathrm{mg} / \mathrm{g}, 0.099 \pm 0.002 \mathrm{mg} / \mathrm{g}, 0.057 \pm 0.002 \mathrm{mg} / \mathrm{g}$, $34.414 \pm 0.844 \mathrm{mg} / \mathrm{g}$, and $1.440 \pm 0.030 \mathrm{mg} / \mathrm{g}$, respectively. The concentrations of gallic acid, protocatechuic acid, protocatechuic aldehyde, $(+)$-catechins, and chlorogenic acid in rattan sheaths were $0.241 \pm 0.005 \mathrm{mg} / \mathrm{g}, 0.032 \pm 0.002 \mathrm{mg} / \mathrm{g}, 0.085 \pm 0.002 \mathrm{mg} / \mathrm{g}, 3.161 \pm 0.084 \mathrm{mg} / \mathrm{g}$, and $12.149 \pm 0.296 \mathrm{mg} / \mathrm{g}$, respectively. In DES extracts of rattan episperm, only (+)-catechins and chlorogenic acid were detected, at concentrations of $11.981 \pm 0.299 \mathrm{mg} / \mathrm{g}$ and $13.538 \pm 0.288 \mathrm{mg} / \mathrm{g}$, respectively. Only gallic acid, protocatechuic acid, and chlorogenic acid were detected in DES extracts of the arillus, at concentrations of $2.465 \pm 0.034 \mathrm{mg} / \mathrm{g}, 0.048 \pm 0.001 \mathrm{mg} / \mathrm{g}$, and $0.66 \pm 0.020 \mathrm{mg} / \mathrm{g}$, respectively. The concentrations of gallic acid, protocatechuic aldehyde, (+)-catechins, and chlorogenic acid in DES extracts from rattan seeds were $0.020 \pm 0.001 \mathrm{mg} / \mathrm{g}, 0.093 \pm 0.002 \mathrm{mg} / \mathrm{g}$, $4.697 \pm 0.051 \mathrm{mg} / \mathrm{g}$, and $7.959 \pm 0.081 \mathrm{mg} / \mathrm{g}$, respectively. In DES extracts from rattan stems, only gallic acid and chlorogenic acid were detected, at concentrations of $0.029 \pm 0.001 \mathrm{mg} / \mathrm{g}$ and $4.831 \pm 0.050 \mathrm{mg} / \mathrm{g}$, respectively.

\subsection{Recovery of Phenolic Compounds from $\mathrm{ChCl}-\mathrm{EG}$}

The use of the AB- 8 macroporous resin to recover the phenolic compounds from $\mathrm{ChCl}$-EG extracts was evaluated. The total recovery rate of all six phenolic compounds by dynamic chromatography at the upper flow rate of $0.5 \mathrm{~mL} / \mathrm{min}$ was $94.4 \%$. Then, ChCl-EG was removed with deionized water and decompression evaporation for reuse. The adsorbed phenolic compounds were then eluted with $70 \%$ ethanol solution at $1.0 \mathrm{~mL} / \mathrm{min}$, and the ethanolic fractions (each $10 \mathrm{~mL}$ ) were collected for HPLC analysis. Finally, the ethanolic eluates containing each respective phenolic compound were combined, each combined eluate was dried with a vacuum evaporator, and the purity and recovery rate were calculated (Table 2).

Table 2. Recovery rates of six phenolic compounds by AB-8 resin.

\begin{tabular}{cccccc}
\hline No. & Phenolic Compounds & $\begin{array}{c}\text { Upper Flow } \\
\text { Rate (mL/min) }\end{array}$ & $\begin{array}{c}\text { Elute Flow } \\
\text { Rate (mL/min) }\end{array}$ & $\begin{array}{c}\text { Recovery } \\
\text { Rates }\end{array}$ & Purity (g/g) \\
\hline 1 & Gallic acid & 0.5 & 1.0 & $93.77 \%$ & $46.57 \%$ \\
2 & Protocatechuic acid & 0.5 & 1.0 & $94.09 \%$ & $42.51 \%$ \\
3 & Protocatechuic & 0.5 & 1.0 & $97.32 \%$ & $51.94 \%$ \\
4 & aldehyde & 0.5 & 1.0 & $97.83 \%$ & $54.33 \%$ \\
5 & (+)-catechins & 0.5 & 1.0 & $94.41 \%$ & $57.64 \%$ \\
6 & Chlorogenic acid & 0.5 & 1.0 & $92.47 \%$ & $67.58 \%$ \\
\hline
\end{tabular}

\section{Materials and Methods}

\subsection{Materials}

\subsubsection{Rattan Materials}

Rattan (Calamoideae faberii) materials (all the parts) were collected from Hainan, China, in October 2016 and were dried in a shaded, well-ventilated area, and then sheared into $1 \mathrm{~cm} \times 1 \mathrm{~cm}$ square pieces.

\subsubsection{Chemicals}

Standards (>98\% purity) of gallic acid, protocatechuic acid, protocatechuic aldehyde, (+)-catechins, chlorogenic acid, and epigallocatechin gallate (EGCG) were purchased from the National Institute for the Control of Pharmaceutical and Biological Products (Beijing, China). Folin-Ciocalteu reagent was obtained from Sigma (St. Louis, MO, USA). Other reagents included choline chloride $(\mathrm{ChCl}: 98 \%$, 
Macklin Biochemical Co., Ltd., Shanghai, China), ethylene glycol (EG: 99\%, Fuyu Fine Chemical Co., Ltd., Tianjin, China), glycol (Gl: 99\%, Tiantian Chemical Testing Factory, Tianjin, China), 1,4-butylene glycol (BDO, 98\%, Guangfu Fine Chemical Co., Ltd., Tianjin, China). Deionized water was purified using a Milli-Q Water Purification system (Millipore, Billerica, MA, USA). Methanol and phosphoric acid (HPLC grade) were purchased from J\&K Chemicals Ltd. (Shanghai, China). All other solvents and chemicals were of analytical grade and were purchased from Beijing Chemical Reagents Co. (Beijing, China). All solutions used for HPLC were filtered through $0.22 \mu \mathrm{m}$ membranes before use.

\subsection{Methods}

\subsubsection{Determination of Total Phenolic Content}

The total phenolic content of the extracts was determined as described elsewhere [35], with modifications. The rattan extract was diluted with distilled water to an appropriate concentration, and then $1 \mathrm{~mL}$ of the diluted sample was mixed with $100 \mathrm{~mL}$ Folin-Ciocalteu reagent (previously diluted with water $1: 1, v / v)$. A saturated sodium carbonate solution $(10 \%, 2 \mathrm{~mL})$ was then added, and the mixture was kept at room temperature for $60 \mathrm{~min}$ before being centrifuged at $3000 \mathrm{r} / \mathrm{min}$ for $5 \mathrm{~min}$. The absorbance of the supernatant was measured at $725 \mathrm{~nm}$.

\subsubsection{RP-HPLC analysis of Phenolic Compounds}

The RP-HPLC system consisted of a Waters 717 automatic sample handling system, an HPLC system equipped with a 1525 binary pump, a 717 automatic column temperature control box, and a 2487 UV-detector (all from Waters, Milford, MA, USA). Chromatographic separation was performed on a HiQ sil-C18 reversed-phase column ( $4.6 \mathrm{~mm} \times 250 \mathrm{~mm}, 5 \mu \mathrm{m}$, KYA TECH Corp., Tokyo, Japan) for the simultaneous determination of six phenolic compounds.

\subsubsection{Preparation of DESs}

DESs were synthesized by a heating method [36]. The hydrogen bond acceptor in each DES was $\mathrm{ChCl}$. This was mixed with a hydrogen bond donor (one of the polyols listed in Section 2.3.1) in an appropriate molar ratio and placed in a reaction flask with magnetic agitation at $80^{\circ} \mathrm{C}$ for $30 \mathrm{~min}$, resulting in the formation of a transparent, homogeneous liquid. Three DESs with different compositions, including ChCl-EG (ethylene glycol), ChCl-Gl (glycerol), and ChCl-BDO (1,4-butylene glycol), were prepared using the three different hydrogen bond donors.

\subsubsection{Extraction of Phenolic Acid Compounds with DESs}

A homogenate-assisted extraction (HAE) method was used to extract phenolic compounds from the rattan materials using the DESs. A $200 \mathrm{~W}$ homogenizer (HANUO-JJ2, Shanghai Hannuo Instrument Co. Ltd., Shanghai, China) was used to grind the materials, and $20.0 \mathrm{~g}$ of the ground material was added to $300 \mathrm{~mL}$ DES solution in the homogenizer. After homogenization for $2.0 \mathrm{~min}$, the extract was cooled to room temperature and then filtered through a $0.45 \mu \mathrm{m}$ filter before total phenolic content analysis.

\subsubsection{HVE Method to Extract Phenolic Acid Compounds}

A homogenate-assisted vacuum-cavitation extraction (HVE) method was used to extract phenolic acid compounds from the rattan materials. A negative-pressure cavitation glass column $(50 \times 4.0 \mathrm{~cm})$ was made in our laboratory and was connected to a $180 \mathrm{~W}$ circulating-water vacuum pump (SHB-III, Great Wall Scientific Industry and Trade Co. Ltd., Zhengzhou, China), to control the air flow rate, and the maximum vacuum can reach to $-0.1 \mathrm{Mpa}$. The device scheme of experiments was according to our previous studies [31].

In the extraction experiments, $20.0 \mathrm{~g}$ material was added to $300 \mathrm{~mL}$ DES solution in the homogenizer. After homogenization for $2.0 \mathrm{~min}$, the material and solvent were transferred to the 
negative-pressure cavitation glass column. After vacuum-cavitation extraction at room temperature, the extracts were filtrated through a $0.45 \mu \mathrm{m}$ filter before total phenolic content analysis and HPLC analysis.

\subsubsection{Recycling of DESs}

Absorption of the phenolic compounds from the DES extracts was conducted based on AB-8 macroporous resin (HaoJu resin Technology Co. Ltd., Tianjin, China) column chromatography [37]. The polar DES was removed with deionized water and decompression evaporation for reuse. The sample was then eluted with $70 \%$ ethanol solution, and the ethanolic fractions were dried with a vacuum evaporator, and redissolved with $10 \%$ methanol for HPLC analysis.

\subsubsection{Statistical Analyses}

Results are expressed as mean values $\pm \mathrm{SD}(n=3)$. Mean values from different experiments were compared by ANOVA using Microsoft Excel software (Microsoft Corporation, Redmond, WA, USA). Differences at $p<0.05$ were considered to be significant.

\section{Conclusions}

Homogenate-assisted vacuum-cavitation extraction (HVE) was used to extract phenolic compounds with deep eutectic solvents (DESs) from different parts of rattan (Palmae), and the extraction mechanisms of homogenate-assisted negative-pressure cavitation have been analyzed in detail. The optimum molar ratio of choline chloride $(\mathrm{ChCl})$ and ethylene glycol $(\mathrm{EG})$ was $1: 3$, the optimum volume ratio of $\mathrm{ChCl}-\mathrm{EG}: \mathrm{H}_{2} \mathrm{O}$ was $6: 4$, the solid-liquid ratio was 1:15, and the extraction time of homogenate and vacuum-cavitation were $2.0 \mathrm{~min}$ and $25 \mathrm{~min}$, respectively. Under the optimum parameters, the extraction yield of total phenolic content was $6.82 \mathrm{mg} / \mathrm{g}$. An RP-HPLC method for the simultaneous detection of six phenolic compounds (gallic acid, protocatechuic acid, protocatechuic aldehyde, (+)-catechins, chlorogenic acid, and EGCG) was established. The content of phenolic acid in different organs of rattan was investigated. The highest total phenolic content was in the fruit tissues (seeds, episperm, and arillus), followed by the leaves (sheath and blade) and then the stem. Chlorogenic acid was the most abundant phenolic compound in all organs except for the arillus. Finally, the recovery of the phenolic compounds from $\mathrm{ChCl}-\mathrm{EG}$ extracts by AB-8 macroporous resin was evaluated. The recovery rates of gallic acid, protocatechuic acid, protocatechuic aldehyde, (+)-catechins, chlorogenic acid, and EGCG were more than 90\%, and the corresponding purities were $46.57 \%-67.58 \%$.

Supplementary Materials: The following are available online. Figure S1: Formation diagram of hydrogen bonds between $\mathrm{ChCl}$ and EG, Figure S2: Effect of water content on the viscosity of DES solution, Table S1: Parameters of homogenate-assisted and vacuum-cavitation extraction.

Author Contributions: Q.C. and J.L. conducted experiment; Y.X. and S.L. (Sha Luo) analyzed data and prepared the Tables and Figures; C.M. and W.L. design this research and wrote this manuscript; S.L. (Shouxin Liu) contributed chemical reagents and analytical tools. Q.C. and J.L. are contributed equally to this work.

Funding: This work was funded by the National Natural Science Foundation of China (31890773, 31500467, 31570567), the National Key Technology R\&D Program (2015BAD14B06), the Postdoctoral Scientific Research Developmental Fund of Heilongjiang Province in 2016 (LBH-Q16001), and the Research Start-up Funding of Introduce Talents in Northeast Forestry University (YQ2015-02).

Acknowledgments: We thank Leo Holroyd, from Liwen Bianji, Edanz Group China (www.liwenbianji.cn/ac), for editing the English text of a draft of this manuscript.

Conflicts of Interest: The authors declare no conflict of interest. 


\section{References}

1. Andrey, S.; Andrey, B.; Marcello, L.; Simone, C.; Vasil, A. Application of deep eutectic solvents in analytical chemistry A review. Microchem. J. 2017, 135, 33-38.

2. Dragan, Z.T.; Zoran, B.T.; Dušica, R.Đ.; Olivera, S.S.; Vlada, B.V. Application of ionic liquids and deep eutectic solvents in biodiesel production: A review. Renew. Sustain. Energy Rev. 2016, 61, 473-500.

3. Yves, P.M.; Maan, H.; Adeeb, H.; Won, F.W.; Mohd, A.H.; Chung, Y.L. Applications of deep eutectic solvents in biotechnology and bioengineering-Promises and challenges. Biotechnol. Adv. 2017, 35, 105-134.

4. Artemiy, A.S.; Michael, A.S.; Maria, P.S.; Elena, N.P.; Alexander, M.T. Choline chloride based deep eutectic solvents as extraction media for separation of n-hexane-ethanol mixture. Fluid Phase Equilib. 2017, 448, 123-127.

5. Najmedin, A.; Mahtab, E. Deep eutectic solvent immobilized on SBA-15 as a novel separable catalyst for one-pot three-component Mannich reaction. Microporous Mesoporous Mater. 2017, 240, 130-136.

6. Sarita, K.; Yogesh, K.T.; Mahendra, K. Deep eutectic solvents (DESs) as eco-friendly and sustainable solvent/catalyst systems in organic transformations. J. Mol. Liq. 2016, 215, 345-386.

7. Arun, K.D.; Mukesh, S.; Dibyendu, M.; Kamalesh, P. Deep eutectic solvents as efficient solvent system for the extraction of-carrageenan from Kappaphycus alvarezii. Carbohydr. Polym. 2016, 136, 930-935.

8. Zhuang, B.; Dou, L.; Li, P.; Liu, E. Deep eutectic solvents as green media for extraction of flavonoid glycosides and aglycones from Platycladi Cacumen. J. Pharm. Biomed. 2017, 134, 214-219. [CrossRef]

9. Veronika, F.; Didier, T.; Werner, K. Eco-friendly one pot synthesis of caffeic acid phenethyl ester (CAPE) via an in-situ formed deep eutectic solvent. Sustain. Chem. Pharm. 2016, 4, 40-45.

10. Zhao, C.J.; Zu, Y.G.; Fu, Y.J. Homogenated extraction of total flavonoids from fruits of sea buckthorn (Hippophae rhamnoides L.). Chem. Ind. For. Prod. 2006, 26, 38-40.

11. Domini, C.; Vidal, L.; Cravotto, G.; Canals, A. A simultaneous, direct microwave/ultrasound-assisted digestion procedure for the determination of total Kjeldahl nitrogen. Ultrason. Sonochem. 2009, 16, 564-569. [CrossRef] [PubMed]

12. Zhang, D.Y.; Zu, Y.G.; Fu, Y.J.; Luo, M.; Wang, W.; Gu, C.B.; Zhao, C.J.; Jiao, J.; Efferth, T. Enzyme pretreatment and negative pressure cavitation extraction of genistein and apigenin from the roots of pigeon pea [Cajanus cajan (L.) Millsp.] and the evaluation of antioxidant activity. Ind. Crops Prod. 2012, 37, 311-320. [CrossRef]

13. Dong, L.; Fu, Y.; Zu, Y.; Li, J.; Li, X.; Efferth, T. Negative pressure cavitation accelerated processing for extraction of main bioactive flavonoids from Radix Scutellariae. Chem. Eng. Process. 2011, 50, 780-789. [CrossRef]

14. Ma, C.; Liu, T.; Yang, L.; Zu, Y.; Wang, S.; Zhang, R. Study on ionic liquid-based ultrasonic-assisted extraction of biphenyl cyclooctene lignans from the fruit of Schisandra chinensis Baill. Anal. Chim. Acta 2011, 689, 110-116. [CrossRef] [PubMed]

15. Ma, C.; Wang, S.; Yang, L.; Zu, Y.; Yang, F.; Zhao, C.; Zhang, L.; Zhang, Z. Ionic liquid-base ultrasonic-assisted extraction of camptothecin and 10-hydroxycamptothecin from Camptotheca acuminata samara. Chem. Eng. Process. 2012, 57-58, 59-64. [CrossRef]

16. Jiao, J.; Wei, F.; Gai, Q.; Wang, W.; Luo, M.; Fu, Y.; Ma, W. A pilot-scale homogenization-assisted negative pressure cavitation extraction of Astragalus polysaccharides. Int. J. Biol. Macromol. 2014, 67, 189-194. [CrossRef] [PubMed]

17. Luo, M.; Yang, L.; Yao, X.; Mu, F.; Zhang, D.; Song, Z.; Qiao, Q.; Fu, Y.; Zu, Y. Optimization of enzyme-assisted negative pressure cavitation extractionof five main indole alkaloids from Catharanthus roseus leaves and itspilot-scale application. Sep. Purif. Technol. 2014, 125, 66-73. [CrossRef]

18. Qi, X.L.; Peng, X.; Huang, Y.Y.; Li, L.; Wei, Z.F.; Zu, Y.G.; Fu, Y.J. Green and efficient extraction of bioactive flavonoids from Equisetum palustre L. by deep eutectic solvents-based negative pressure cavitation method combined with macroporous resin enrichment. Ind. Crops Prod. 2015, 70, 142-148.

19. Wang, X.; Wei, W.; Zhao, C.; Li, C.; Luo, M.; Wang, W.; Zu, Y.; Efferth, T.; Fu, Y. Negative-pressure cavitation coupled with aqueous two-phase extraction and enrichment of flavonoids and stilbenes from the pigeon pea leaves and the evaluation of antioxidant activities. Sep. Purif. Technol. 2015, 156, 116-123. [CrossRef]

20. Zhang, D.; Yao, X.; Luo, M.; Zhao, C.; Fu, Y. Optimization of negative pressure cavitation-microwave assisted extraction of yellow horn seed oil and its application on the biodiesel production. Fuel 2016, 166, 67-72. [CrossRef] 
21. Mohan Ram, H.Y.; Tandon, R. Bamboo and rattans: From riches to rags. Proc. Indian Nat. Sci. Acad. 1997, 63, 245-267.

22. Dransfield, J.A. A Manual of the Rattans of the Malay Peninsula; Forest Department, Ministry of Primary Industries: Kuala Lumpur, Malaysia, 1979; Volume 23, p. 270.

23. Widayati, A.; Carlisle, B. Impacts of rattan cane harvesting on vegetation structure and tree diversity of Conservation Forest in Buton, Indonesia. For. Ecol. Manag. 2012, 266, 206-215. [CrossRef]

24. Chandrasekara, A.; Shahidi, F. Determination of antioxidant activity in free and hydrolyzed fractions of millet grains and characterization of their phenolic profiles by HPLC-DAD-ESI-MSn. J. Funct. Foods 2011, 3, 144-158. [CrossRef]

25. Terpinc, P.; Cigić, B.; Polak, T.; Hribar, J.; Požrl, T. LC-MS analysis of phenolic compounds and antioxidant activity of buckwheat at different stages of malting. Food Chem. 2016, 210, 9-17. [CrossRef] [PubMed]

26. Sumczynski, D.; Kotásková, E.; Družbíková, H.; Mlček, J. Determination of contents and antioxidant activity of free and bound phenolics compounds and in vitro digestibility of commercial black and red rice (Oryza sativa L.) varieties. Food Chem. 2016, 211, 339-346. [CrossRef] [PubMed]

27. Gabriele, M.; Gerardi, C.; Longo, V.; Lucejko, J.; Degano, I.; Pucci, L.; Domenici, V. The impact of mycorrhizal fungi on Sangiovese red wine production: Phenolic compounds and antioxidant properties. LWT-Food Sci. Technol. 2016, 72, 310-316. [CrossRef]

28. Tourtoglou, C.; Nenadis, N.; Paraskevopoulou, A. Phenolic composition and radical scavenging activity of commercial Greek white wines from Vitis vinifera L. cv. Malagousia. J. Food Compos. Anal. 2014, 33, $166-174$. [CrossRef]

29. Aksoy, L.; Kolay, E.; Ağılönü, Y.; Aslan, Z.; Kargığlu, M. Free radical scavenging activity, total phenolic content, total antioxidant status, and total oxidant status of endemic Thermopsis turcica. Saudi J. Biol. Sci. 2013, 20, 235-239. [CrossRef]

30. Blum-Silva, C.H.; Chaves, V.C.; Schenkel, E.P.; Coelho, G.C.; Reginatto, F.H. The influence of leaf age on methylxanthines, total phenolic content, and free radical scavenging capacity of Ilex paraguariensis aqueous extracts. Rev. Bras. Farmacogn. 2015, 25, 1-6. [CrossRef]

31. Sun, Y.; Yang, K.; Cao, Q.; Sun, J.; Xia, Y.; Wang, Y.; Li, W.; Ma, C.; Liu, S. Homogenate-assisted vacuum-powered bubble extraction of Moso bamboo flavonoids for on-line scavenging free radical capacity analysis. Molecules 2017, 21, 1156. [CrossRef] [PubMed]

32. Xia, Y.; Wang, Y.; Li, W.; Ma, C.; Liu, S. Homogenization-assisted cavitation hybrid rotation extraction and macroporous resin enrichment of dihydroquercetin from Larix gmelinii. J. Chromatogr. B 2017, 82, $204-217$. [CrossRef] [PubMed]

33. Liu, W.; Fu, Y.J.; Zu, Y.G.; Kong, Y.; Zhang, L.; Zu, B.S.; Efferth, T. Negative-pressure cavitation extraction for the determination of flavonoids in pigeon pea leaves by liquid chromatography-tandem mass spectrometry. J. Chromatogr. A 2009, 1216, 3841-3850. [CrossRef]

34. Zhang, D.Y.; Zhang, S.; Zu, Y.G.; Fu, Y.J.; Kong, Y.; Gao, Y.; Zhao, J.T.; Efferth, T. Negative pressure cavitation extraction and antioxidant activity of genistein and genistin from the roots of pigeon pea [Cajanus cajan (L.) Millsp.]. Sep. Purif. Technol. 2010, 74, 261-270. [CrossRef]

35. Ragazzi, E.; Veronese, G. Quantitative analysis of phenolic compounds after thin layer chromatography. J. Chromatogr. 1973, 77, 369-375. [CrossRef]

36. Duan, L.; Dou, L.L.; Guo, L.; Li, P.; Liu, E.H. Comprehensive evaluation of deepeutectic solvents in extraction of bioactive natural products. ACS Sustain. Chem. Eng. 2016, 4, 2405-2411. [CrossRef]

37. Dai, Y.; Witkamp, G.J.; Verpoorte, R.; Choi, Y.H. Natural deep eutectic solvents asa new extraction media for phenolic metabolites in Carthamus tinctorius L. Anal. Chem. 2013, 85, 6272-6278. [CrossRef]

Sample Availability: Samples of the compounds are available from the authors. 